\title{
Research on Allocation of Gross Electromagnetic Pollution Emission Right in Power Quality Markets
}

\author{
Guanghou Jin, Gengyin Li, Member, IEEE, Ming Zhou, Student Member, IEEE, \\ and Yixin Ni, Senior Member, IEEE
}

\begin{abstract}
Management of Power Quality (PQ) suffers more pressure from economy and social equity, it is necessary to control electromagnetic pollution emitted from both electric utilities and customers. Calculation of optimal Emission Right (ER) gross and its distribution is an important content of controlling electromagnetic pollution, and it should be worked out based on cooperative game. This paper analyses game actions among all members in one Point of Common Connection (PCC) for pursuing ER and high $P Q$, and clarifies the highest price of ER and PQ service that is acceptable for gamers. This paper adopts uniform price sealed auction model to make gamers take the acceptable highest price of ER and PQ service as their bidding price, and PQ Supervision Department (PQSD) can make full use of their information from auction, then the calculated ER gross can satisfy Pareto optimality. That gross can maximize social integrative benefits. This auction model also proposes the Bayes Nash equilibrium for the optimal distribution of ER among all gamers. This equilibrium can optimize distribution of social and electromagnetic resource. Examples indicate that the proposed model for optimal gross and distribution of ER based on game theory is feasible and effective.
\end{abstract}

Index Terms--Power quality; electricity market; power quality market; game theory

\section{INTRODUCTION}

$\mathrm{E}^{1}$ LECTRICAL loads trend to diversity and complexity. So much nonlinear, impactive and unbalanced loads deteriorate power quality of network. At the same time, lots of computer systems, robots and high-tech industries require higher and higher Power Quality (PQ). Approximately estimated by EPRI in 2000, economic loss relating to PQ is 26 billion dollar per year in USA [1]. Conflicts caused by Power Quality (PQ) are deepening increasingly. An important reason is that electromagnetic pollution has external cost, that means some one emits electromagnetic pollution (conductive) into one Point of Common Connection (PCC), then all customers connected into this PCC will suffer economic losses from it.

This work was supported in part by Specialized Research Fund for the Doctoral Program of Higher Education, the State Education Ministry of China (No. 20040079002) and Preliminary Research Fund for Significant Subject, North China Electric Power University.

Guanghou Jin, Gengyin Li, and Ming Zhou are with the School of Electrical Engineering, North China Electric Power University, Baoding 071003, Hebei Province, P.R.China (e-mail: jingh001@126.com, ligy@ncepu.edu.cn, zhouming@ncepu.edu.cn).

Yixin Ni is with the Department of Electrical and Electronic Engineering, The University of Hong Kong, Hong Kong SAR, P.R.China. (e-mail: yxni@eee.hku.hk).
Now there is lack for incentives to decision-makers considering the impacts caused by electromagnetic pollution when they make decisions. Like other natural environment, electromagnetic environment is also public property. PQ management suffers pressure from economy and social equity requirements. According to "environmental economics" [2], it is necessary to control electromagnetic pollution from both electric utilities and customers.

To control electromagnetic pollution includes three parts: restricting pollution gross, optimizing distribution of Emission Right (ER) and charging for pollution. Restricting pollution gross means to maintain PCC on optimal polluted level where the sum of loss caused by PQ disturbances, mitigation cost for PQ disturbances and improvement cost for higher PQ in the whole PCC is the least. Optimizing distribution of ER is to make full use of electromagnetic environment directly, and indirectly induce optimal investment for mitigating PQ disturbances. Charging for pollution is to transfer external cost to interior. It bases on ER quantity that means someone with more ER should pay more while others with less ER can pay less. That is equitable and can create incentives for decision-makers to consider external cost of pollution.

Optimal gross and distribution of ER both vary with loads and networks. They should be worked out through optimal programming method. Therefore, the information about electric characters, the economic losses caused by $\mathrm{PQ}$ disturbances, the mitigation and improvement efficiency of electric utility and customers needs to be collected. It is infeasible without PQ Supervision Department (PQSD). Administrative way alone in market may be ineffective and may cause corruption easily. Cooperative game means many players ally a coalition, and shoot for utmost profit of this coalition, after that they will distribute the profit inside through game [3]-[4]. It is just fit for researching optimal gross and distribution of ER. That ensures the study on market policy and market players' action accords with actual cases.

\section{Game Analysis to Electromagnetic EnVIRONMENT}

Suppose there are $n$ rational players in a certain PCC, they emit electromagnetic pollution when they operate normally, at the same time they maybe need to improve PQ reasonably to ensure normal production. Electromagnetic environment of this PCC is public resource for all players. However, everyone would like to enjoy favorable PQ and not willing to bear the 
obligation of protecting electromagnetic environment. Everyone attempts to maximize its benefit through correct game strategy.

\section{A. Basic Assumptions}

All actions of players are classified into two types of independent game process named as "applying for ER" and "applying for PQ service". Considering customers emitting electromagnetic pollution as electric current sources (except reactive current), whose output impedances are diverse, polluting ability to PCC of various customers is different. Therefore, absolute polluting current needs to be amended. A polluting ability coefficient, named $F$, is introduced, whose value is reciprocal of polluting current that cause PCC unit voltage distortion. For example, $10 \mathrm{~A} 3^{\text {rd }}$ harmonic current of a certain customer causes $1 \mathrm{~V} 3^{\text {rd }}$ harmonic voltage of PCC, so this customer's polluting ability coefficient of $3^{\text {rd }}$ harmonic current $F_{h 3}=0.1$; if $5 \mathrm{~A}$ negative-sequence current causes $1 \mathrm{~V}$ negative-sequence voltage of PCC, then this customer's coefficient of negative-sequence current $F_{n e g}=0.2$; if surge current whose amplitude is $5 \mathrm{~A}$ causes sag of PCC whose drop of voltage is $1 \mathrm{~V}$, its coefficient of surge current $F_{s}=0.2$. The rest may be deduced similarly, all customers' absolute polluting current can be standardized into relative polluting current based on polluting ability to PCC, whose unit is defined as $\AA$ so there is a uniform criterion to appraise polluting current of customer.

Variables $x_{i}, y_{i} \in[0,+\infty](i=1,2, \cdots, n)$ are introduced, where $x_{i}$ means the emitted pollution quantity of player $i, y_{i}$ means the pollution quantity margin that player $i$ feels less than the pollution gross in PCC, to take improving action or buy PQ service. All $x_{i}$ and $y_{i}$ have been united by polluting ability coefficient $F$. For example, absolute polluting current of player $i$ is $50 \mathrm{~A}$, and its polluting ability coefficient $F=0.1$, so its pollution quantity $x_{i}=5 \AA \quad X=\sum_{i=1}^{n} x_{i}$ means the pollution gross of all players. Suppose any player will not influence others by their improvement for higher PQ. Electromagnetic environment has its capability to endure pollution, and it will be drastically damaged if pollution exceeds its limit. Then power system cannot run normally, and players cannot operate either. So there is a maximal capacity $X_{\max }$.

\section{B. Nash Equilibrium of Game [5]-[7]}

There are five kinds of ER: harmonic ER, unbalanced current ER, surge current ER, fluctuant \& flickering current ER and reactive current ER [8,9]. In the game of "applying for ER", if pollution gross $X^{*}$ is given, players need to compete for it. Every player should decide how much ER $x_{i}^{*}\left(x_{i}^{*}\right.$ $>0$ ) be bought and how much bid-price $p_{i}^{*}$ be provided to maximize its benefit. For $X^{*}$ is given, game result makes no difference to any players' loss caused by PQ disturbance. The benefit created by ER to players is described as follows

$$
H_{i}\left(x_{1}, \cdots, x_{i}, \cdots, x_{n}\right)=x_{i}\left[v_{i}\left(x_{i}\right)-p_{i}\right] \quad(i=1,2, \cdots, n)
$$

where $p_{i}$ means unit price of ER in practice, $v_{i}\left(x_{i}\right)$ means average expense saved for player $i$ through emitting unit pollution. When $X<X_{\max }, v(x)>0$; When $X \geq X_{\max }, v(x)=0$ (this means electromagnetic environment has been polluted so badly that players can not work any longer). All players require ER create benefit for them, so

$$
p_{i}<v_{i}\left(x_{i}\right)
$$

Equation (2) means that maximal unit price of ER pervious to players is average expense saved from emitting unit pollution.

To one player, variation of $v$ caused by additional unit pollution is so little that can be neglected. However, to dissimilar player, $v$ is different due to technique and production efficiency. So there is

$$
\left\{\begin{array}{c}
\partial v / \partial x=0 \\
v_{i} \neq v_{j}(i \neq j)
\end{array}\right.
$$

Equation (3) means that $v_{i}\left(x_{i}\right)$ is constant to a certain player. As long as (2) is satisfied, more ER can create more benefits. Furthermore, any players' victory or defeat in game is not decided by ER quantity they bid. So ER-quantity $x_{i}^{*}$ bidding by all players should be their maximal polluting capability, and bid-price $p_{i}^{*}$ should be decided by their mitigating efficiency, independent of $x_{i}^{*}$.

Pollution gross is limited, so higher unit bid-price $p_{i}^{*}$ will be helpful to win game, and lower will lose chance of winning game. The strategies adopted by players are decided by the gaming mode PQSD adopted.

In the game of "applying for PQ service", function $c_{i}(X)$ is introduced, that means additional production cost added to player $i$ by additional unit pollution when gross is $X$ in PCC (worse PQ deteriorates work environment, then economic loss rises, production eligibility rate declines, and production efficiency drops, so production cost increases.). If pollution gross $X^{*}$ is given, every player should decide how much PQ service $y_{i}^{*}$ be bought and how much bid-price $q_{i}^{*}$ be provided to maximize its benefit. The benefit created by PQ service is computed as following

$$
M_{i}\left(y_{i}\right)=\int_{0}^{y_{i}} c_{i}\left(X^{*}-y_{i}\right) d y_{i}-y_{i} q_{i} \quad(i=1,2, \cdots, n)
$$

Equation (4) indicates that improving PQ has two opposite effects. One is PQ improvement can drop production-cost, and the other is it will cost $y_{i} q_{i}$ or have to equip improving devices, such as DVR, UPQC and so on. General speaking, to improve PQ separately is very expensive. Therefore, the value of $\mathrm{PQ}$ service is dispersion of reduced production cost subtracting PQ service expense.

If pollution gross $X^{*}$ is given, what is the maximal unit price of PQ service pervious to a player with PQ service $y_{i}^{*}$ ? Derivative of function $M_{i}\left(y_{i}\right)$ means the benefit created by unit PQ service when pollution gross is $X^{*}$,

$$
\partial M_{i} / \partial y_{i}=c_{i}\left(X^{*}-y_{i}\right)-q_{i}
$$

Equation (5) indicates that the benefit created by unit PQ service varies with $y_{i}$. The reason is PQ felt by players rises when they accept PQ service, so marginal production cost reduced by unit PQ service varies. When PCC polluted level 
is low, $c$ of all players caused by additional unit pollution will increase and some may be sharply; after pollution gross reaches $X_{c}, c$ will drop down with $X$ increasing, and different player has different $X_{c}$; when $X<X_{\max }, c(X)>0$; when $X \geq X_{\max }$, $c(X)=0$. So, it is described as following

$$
\left\{\begin{array}{c}
\partial c / \partial X>0\left(0<X<X_{c}\right) \\
\partial c / \partial X=0\left(X=X_{c}\right) \\
\partial c / \partial X<0\left(X_{c}<X<X_{\max }\right) \\
\partial c / \partial X=0\left(X_{\max } \leq X\right)
\end{array}\right.
$$

Equation (6) indicates that $c(X)$ is a parabola adown, instead of monotonic function. When pollution gross is $X^{*}, \mathrm{PQ}$ service may increase or drop $c\left(X^{*}\right)$ for dissimilar players. Exclusive criterion for customers to buy PQ service with quantity $y_{i}^{*}$ is that should create benefit. PQ service price is constant provided by Power Quality Service Company (PQSC), while $c\left(X^{*}-y\right)$ varies, so customers can't ensure each parts of PQ service they bought can create benefit for them. But they can assure their marginal PQ service create benefit, that is:

$$
c_{i}\left(X^{*}-y_{i}\right)-q_{i}>0 \Rightarrow q_{i}<c_{i}\left(X^{*}-y_{i}\right)
$$

Equation (7) means that the maximal unit price of PQ service with quantity $y_{i}$ pervious to a player must be less than production cost reduced by marginal unit PQ service. If unit price of PQ service is higher than $c_{i}\left(X^{*}-y_{i}\right)$, customer will cut down PQ service quantity.

Suppose player $i$ buys PQ service $y_{i}^{*}=1 \AA$ when pollution gross $X^{*}=100 \AA$ The maximal unit price of PQ service pervious to player $i$ is $c_{i}(100)$ obviously.

If player $i$ changes its mind, and want to buy $y_{i}^{*}=10 \AA$, the benefit created by PQ service is

$$
M_{i}\left(y_{i}\right)=\int_{0}^{10} c_{i}\left(100-y_{i}\right) d y_{i}-10 q_{i}
$$

If player $i$ pays $c_{i}(100)$ as unit price $q_{i}$ for PQ service, substituting it into (8) and applying intermediate value theorem yields

$$
\begin{aligned}
M_{i}\left(x_{i}\right) & =\int_{0}^{10} c_{i}\left(100-x_{i}\right) d x_{i}-10 c_{i}(100) \\
& =10 \times\left[c_{i}(100-\lambda)-c_{i}(100)\right]
\end{aligned}
$$

where $\lambda$ is a value within $[0,10]$. Equation (6) and (9) indicate that the production cost reduced by PQ service $y_{i}^{*}=10 \AA$ may be less than what has paid for that. To buy PQ service like that sustains losses in business, nobody will do.

Analysis has indicates that bid-price $q_{i}^{*}$ for PQ service is associated with its quantity $y_{i}^{*}$ to be applied. In a PCC with pollution gross $X^{*}$, for player $i, 0<X^{*}<X_{c}$ comes into existence, if player $i$ wants to increase its quantity $y_{i}^{*}$ of PQ service, its bid-price $q_{i}^{*}$ must be knocked down, then it will lose the chance of winning game. On the contrary, application of less PQ service will have more chance to win. The strategies adopted by players are decided by the gaming mode PQSD adopted.

If considering the two games independently, all the ER and PQ service can be sold, and Nash equilibrium of games can be actualized, as long as unit price of ER or pollution gross $X^{*}$ of $\mathrm{PCC}$ is given.

\section{Pareto Optimality of Game [10]-[11]}

Let $V(X)$ be the marginal expense saved for PCC through emitting unit pollution when pollution gross is $X$. With gross increasing, number of players emitting pollution grows, but marginal expense saved through emitting unit pollution drops leapingly. It is described as following

$$
V\left(X^{*}\right)=\min [v(x)]=v_{i}\left(x_{i}^{*}\right) \quad\left[x_{i}^{*}>0, i \in(1,2, \ldots, n)\right]
$$

Player $i$ is called as the marginal pollution source when pollution gross is $X^{*}$.

Let $C(X)$ be the marginal production cost added to PCC by additional unit pollution when gross is $X$ in PCC. With gross increasing, number of players accepting PQ service grows, so the components of $C(X)$ increase constantly, and the value of $C(X)$ will alter continuously. It is described as following

$$
C(X)=\sum_{i=1}^{n} \min \left[c_{i}(X), q\right]
$$

where $q$ means the unit price of PQ service in practice.

Based on the optimization condition, the marginal benefit must be equal to the marginal cost, optimal pollution gross $X_{\mathrm{opt}}$ will satisfy the following equation

$$
V\left(X_{\mathrm{opt}}\right)=C\left(X_{\mathrm{opt}}\right)
$$

If the right side of (12) is less than the left, that means electromagnetic environment is not be made the best use. On the contrary, that the left side is less than the right means mitigation of PCC is not enough. These two conditions both depart from Pareto optimization. Without participation of PQSD, "non-cooperative game" cannot ensure (12) coming into existence, PCC can not run on the most economical pollution level, which should be calculated by PQSD based on comprehensive information of all players. After that, it will be distributed to players through appropriate method.

To master PQ sensitivity $c_{i}$ in different pollution levels and mitigation efficiency $v_{i}$ of all players exactly is the key to calculate the optimal pollution gross of PCC. Appropriate ER distribution mode will be helpful for PQSD to do that.

\section{Uniform-Price Sealed Auction Game Model}

Auction is a typical offspring of market economy, and now it has become a popular international bargaining means [12]. Upwards-price auction, downwards-price auction, uniformprice (or second-price) auction, different-price auction and both sides auction are several modes in common uses. Their application ranges and objects are different.

Because it has high economic efficiency and potential of increasing income, the uniform-price auction mode is adopted widely. This is a kind of sealed auction. If there is only one object, the bidder who provides the highest price will get it with the second highest price. So it is also called second-price auction mode. If there are multi-objects for auction, secondprice auction turns to uniform-price auction, because all successful bargainees will get the objects with same price. Some one calls this kind of auction as marginal price auction. 
In PQM, ER with different quantity will be auctioned at the same time, so it belongs to multi-objective auction.

\section{A. Analysis to Bidding}

Suppose PQSD want to confirm the optimal pollution gross of a certain PCC and distribute ER to all players through uniform-price sealed auction. All bidders are required to submit requisitions sealed, that include bid information about ER quantity $x_{i}^{*}$, bid-price $p_{i}^{*}$ of unit ER, and bid-price $q_{j k}^{*}$ of unit PQ service on different pollution levels $X_{k}$. During uniform-price sealed auction, all bidders will provide their highest estimation for ER and PQ service as their bid-prices. Because that only decide whether they can bid successfully, not be their actual prices to pay. Debasing bid-price will lose the chance of acquiring profit, and bidding up will risk sustaining losses in business. So substituting unit bid-price $p_{i}^{*}$ and $q_{j k}^{*}$ into (2) and (7), PQ sensitivity $c_{i}$ in different pollution levels and mitigation efficiency $v_{i}$ of all players will be clear. That provide important data for calculating optimal pollution gross of PCC.

Because unit bid-price $q_{i}^{*}$ for PQ service is restricted by corresponding quantity $x_{i}^{*}$ to be applied, on any pollution level $X_{k}^{*}$, there can be many combination of quantity $y_{i k}^{*}$ and corresponding $q_{j k}^{*}$. For convenience, all players are required to provide only one combination of unit quantity PQ service and corresponding $q_{j}^{*}$ on each pollution level. Finally this requisition whose $q_{j}^{*}$ is higher than $q$ provided by Power Quality Service Company (PQSC), can create benefit for customers (computed based on data provided by customers) and corresponding $X_{k}$ is less than optimal pollution gross $X_{\mathrm{opt}}$ can be satisfied. Bargaining-price is $q$ provided by PQSC, and bargaining quantity is dispersion of $X_{\mathrm{opt}}$ subtracting $X_{k}$ where $q_{j}^{*}$ exceeds $q$ the first time. In order to improve efficiency of PQ service and debase its price, competition must be introduced into $\mathrm{PQ}$ service, and $\mathrm{PQSC}$ must bid for right to provide PQ service. The PQSC providing lower price will win, this can ensure the price of PQ service in practice close to its actual value.

PQSD researches on the information of all bidders, there must be a pollution level $X_{k}^{*}$ whose marginal pollution source can satisfy the following

$$
v_{j}=\sum_{i=1}^{n} \min \left[c_{i}\left(X_{k}^{*}\right), q\right]
$$

The left of (13) is the marginal benefit of marginal pollution source $j$, and the right is sum of marginal cost in the whole PCC. Equation (13) is equal to (12).

The optimal pollution gross $X_{k}^{*}$ of PCC can be worked out from (13). Then to find out the prices higher than $p_{j}^{*}$, the ER requisitions corresponding to those prices will success. Bargaining-price is the highest bid-price provided by those unsuccessful bidders. The result is Nash equilibrium of distribution satisfying Pareto optimization

$$
x^{*}=\left(x_{1}^{*}, \cdots, x_{i}^{*}, \cdots, x_{n}^{*}\right)
$$

Because dissimilar players have different PQ sensitivity and mitigation efficiency, the value of same ER is diverse to them. To those players with low marginal mitigation cost, anything will be all right as long as they increase investment a little. If the expense of ER is more than their investment in mitigation, bidding for ER is unreasonable, it does not accord with "rational players" in game. So ER is inessential to them, their bid-prices must be low. To those players with high marginal mitigation cost, to reduce their pollution by themselves maybe very expensive, as long as bidding for ER is cheaper than mitigation cost, it is profitable to do it. So ER is valuable to them, they can bear high unit price.

During auction, no bidder knows others how much evaluation for ER, so they do not know bid-prices of others. This kind of game is an incomplete information game. Because all requirements are submitted in seal, the game decision of all bidders can be considered at the same time. It can be called static game. So this is an incomplete information static game, its equilibrium is called Bayes Nash equilibrium.

\section{B. Advantages of Uniform-price Sealed Auction}

Uniform-price sealed auction is appropriate to work out optimal pollution gross and to distribute ER. There are two advantages as following:

First, uniform-price sealed auction makes PQSD can discern comprehensive information of all players. Then they will work out an optimal pollution gross close to the most economical pollution level of PCC. During uniform-price sealed auction, all bidders submit their bid-price $p_{i}^{*}$ of unit ER and bid-price $q_{j k}^{*}$ of unit PQ service on different pollution level $X_{k}$, and all the prices will be their real highest evaluation. Equations (2) and (7) indicate that all unit bid-prices $p_{i}^{*}$ and $q_{j k}^{*}$ just be mitigation efficiency $v_{i}$ and PQ sensitivity $c_{i}$ on different pollution levels of all players. Based on this information, PQSD can discern PQ sensitivity of the whole PCC easily. Then the optimal pollution gross $X^{*}$ can be confirmed that satisfies Pareto optimization condition (12).

Second, uniform-price sealed auction is more equitable to all bargainees, even it can promote development of technique. In other auction modes, the bidders who provide higher prices will buy ER or PQ service with higher prices. In PQM, it is reasonable to buy ER and PQ service without any difference with same unit price. It will provide incentives for players to improve technique and production efficiency.

\section{EXAMPLE}

Following example can testify feasibility to work out optimal pollution gross and optimal distribution of ER based on game theory. Harmonics is a kind of electromagnetic pollution. Suppose game players A, B C, D, E and F are connected to one bus, as shown in Fig.1, E and F are PQSC, whose function is to improve PQ level for customers.

Real information of all players is given in Table I, where units of $i_{\max }$ and $x_{\max }$ are A and $\AA$, and units of both $c$ and $v$ are $\$ / A$ day. For every player is opponent to each other, this information is privacy. Information of ER-requisitions offered by all players is given in Table II, where data is ER quantity $x_{i}^{*}$ and bid-price $p_{i}^{*}$ of unit ER. Supply and demand information of 
PQ service offered by all players is given in Table III, whose unit is $\$ / A$ day.

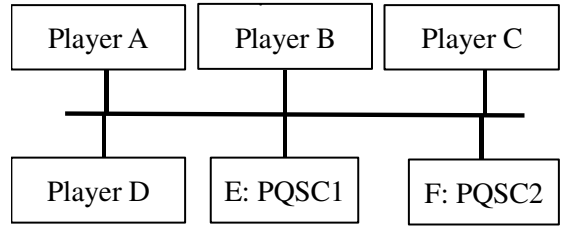

Fig. 1 Six players in game.

TABLE I

REAL INFORMATION OF ALL PLAYERS

\begin{tabular}{ccccccccccc}
\hline & $i_{\max }$ & $F_{h}$ & $x_{\max }$ & $v$ & $c(50)$ & $c(55)$ & $c(60)$ & $c(65)$ & $c(70)$ & $c(75)$ \\
\hline $\mathrm{A}$ & 300 & 0.1 & 30 & 350 & 10 & 15 & 25 & 35 & 45 & 60 \\
$\mathrm{~B}$ & 200 & 0.2 & 40 & 190 & 25 & 40 & 55 & 70 & 90 & 110 \\
$\mathrm{C}$ & 150 & 0.3 & 45 & 140 & 10 & 20 & 30 & 40 & 45 & 50 \\
$\mathrm{D}$ & 75 & 0.4 & 30 & 110 & 15 & 25 & 40 & 60 & 80 & 100 \\
\hline
\end{tabular}

TABLE II

BID-INFORMATION OF APPLYING ER

\begin{tabular}{lllll}
\hline & $\mathrm{A}$ & $\mathrm{B}$ & $\mathrm{C}$ & $\mathrm{D}$ \\
\hline$x_{i}^{*}(\mathrm{~A})$ & 30 & 40 & 45 & 30 \\
\hline$p_{i}^{*}($ \$/Aday $)$ & 350 & 190 & 140 & 110 \\
\hline
\end{tabular}

TABLE III

BID-INFORMATION OF APPLYING AND SUPPLY PQ SERVICE

\begin{tabular}{ccccccc}
\hline & 50 & 55 & 60 & 65 & 70 & 75 \\
\hline $\mathrm{A}$ & 10 & 15 & 25 & 35 & 45 & 60 \\
$\mathrm{~B}$ & 25 & 40 & 55 & 70 & 90 & 110 \\
$\mathrm{C}$ & 10 & 20 & 30 & 40 & 45 & 50 \\
$\mathrm{D}$ & 15 & 25 & 40 & 60 & 80 & 100 \\
\hline PQSC1 & & & & 50 & & \\
PQSC2 & & & 55 & & \\
\hline
\end{tabular}

Marginal expense $V(X)$ saved for PCC through emitting unit pollution on different pollution levels can be discerned according to Table II. It is described as follows

$$
V(X)=\left\{\begin{array}{cc}
350 & (X \leq 30) \\
190 & (30<X \leq 70) \\
140 & (70<X \leq 115) \\
110 & (115<X \leq 145)
\end{array}\right.
$$

Concluded from Table III, unit price of PQ service provided by $\mathrm{PQSC} 1$ is lower than $\mathrm{PQSC} 2$. All unit prices those are provided by requisitions for $\mathrm{PQ}$ service and higher than the price of PQSC1 should be displaced by 50\$/Aday, as shown in Table IV.

Marginal production cost $C(X)$ added to $\mathrm{PCC}$ by additional unit pollution on different pollution levels can be discerned according to Table IV, as shown in Table V, where its unit is $\$ /$ day.
TABLE IV

BID-INFORMATION OF PQ SERVICE (AFTER REPLACED)

\begin{tabular}{lllllll}
\hline & 50 & 55 & 60 & 65 & 70 & 75 \\
\hline A & 10 & 15 & 25 & 35 & 45 & 50 \\
B & 25 & 40 & 50 & 50 & 50 & 50 \\
C & 10 & 20 & 30 & 40 & 45 & 50 \\
D & 15 & 25 & 40 & 50 & 50 & 50 \\
\hline
\end{tabular}

TABLE V

MARGINAL Cost $C(X)$ OF PCC ON DiVERSE POLLUTED LEVEL

\begin{tabular}{ccccccc}
\hline & 50 & 55 & 60 & 65 & 70 & 75 \\
\hline$C(X)$ & 60 & 100 & 145 & 175 & 190 & 200 \\
\hline
\end{tabular}

Comparing Table V and (15), Pareto optimization (13) can be satisfied when $X=70$. That means optimal pollution gross is

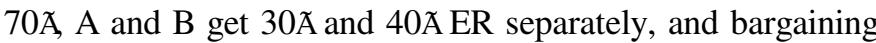
price is $140 \$ / A$ day. For bid-prices $q_{j k}^{*}$ provided by B and D have exceeded bid-price of PQSC1 since $X=60$ and $X=65$ separately, they get $10 \AA$ and $5 \AA \mathrm{PQ}$ service with price 50\$/Aday.

Game result indicates that A and B with the highest mitigation cost will get $\mathrm{ER}, \mathrm{B}$ and $\mathrm{D}$ with the most sensitive to $\mathrm{PQ}$ will get $\mathrm{PQ}$ service, and $\mathrm{PQSC} 1$ with higher efficiency will win the chance to supply PQ service. Alteration of PCC integrated benefit when pollution gross is $65 \AA 70 \AA$ and $75 \AA$ separately is contrasted in Table VI (ER is distributed through uniform-price sealed auction). It is computed as following:

$$
\Delta L=\Delta X[V(X)-C(X)]
$$

TABLE VI

$\triangle L$ VARYING WITH $\Delta X$ IN DIFFERENT $X$

\begin{tabular}{ccccccc}
\hline$X(\mathrm{~A})$ & \multicolumn{2}{c}{65} & \multicolumn{2}{c}{70} & \multicolumn{2}{c}{75} \\
\hline$\Delta X(\mathrm{~A})$ & -1 & +1 & -1 & +1 & -1 & +1 \\
\hline$\Delta L(\$ /$ day $)$ & +15 & -15 & $0+$ & $0+$ & -60 & +60 \\
\hline
\end{tabular}

Table VI indicates that additional pollution and mitigation both increase economic loss of PCC when pollution gross is $70 \AA$ But when pollution gross is $65 \AA$ or $75 \AA$, there always exist a direction to reduce economic loss for PCC. It testifies that cooperative game can maximize social integrated benefits.

If one player, take $\mathrm{A}$ as an example, tries to reduce pollution gross through raising his PQ service bid-price, which exceeds its real value, as shown in Table VII.

TABLE VII

BIDDING PRICE $P_{I}^{*}$ OF PLAYER A IS RAISED

\begin{tabular}{lllllll}
\hline & 50 & 55 & 60 & 65 & 70 & 75 \\
\hline$p_{i}^{*}$ & 40 & 50 & 60 & 70 & 80 & 90 \\
\hline
\end{tabular}

Suppose bidding price $p_{i}^{*}$ of others same to forenamed, so the marginal production cost added to PCC by additional unit pollution on different pollution levels turns to $C^{\prime}(X)$, as shown in Table VIII, where its unit is \$/day. 
TABLE VIII

Marginal Cost $C^{\prime}(X)$ OF PCC ON Diverse Polluted LEVELS

\begin{tabular}{ccccccc}
\hline & 50 & 55 & 60 & 65 & 70 & 75 \\
\hline$C^{\prime}(X)$ & 90 & 135 & 170 & 190 & 195 & 200 \\
\hline
\end{tabular}

Comparing Table VIII and (15), the optimal pollution gross is $65 \AA$ less than forenamed, that is intention of A raising his PQ service bid-price. There are three aftereffects. Firstly, $5 \AA \mathrm{ER}$ is reduced from player $\mathrm{B}$, who must pay additional $(190-140) \times 5=250 \$$ (according to Table II) to mitigate pollution every day, furthermore PCC as a system must pay additional $190 \times 5=950 \$$ (according to (15)) to mitigate pollution every day. Secondly, production-cost of PCC is debased, its value is between $175 \times 5=875 \$$ and $190 \times 5=950 \$$ (according to Table V) every day. Thirdly, player A must pay $50 \times 10=500 \$$ for $10 \AA$ PQ service. PQ service and pollution gross descending can create profit for A approximate to $(15+45) \times(70-55) / 2=450 \$$ (according to Table IV) every day. Forenamed data indicates that because A raises his PQ service bid-price, integrated benefit of PCC descends, and both A and B suffer economic loss. Therefore, rational players will not take this kind of game strategy.

By the way, anyone raising ER bid-price also will risk economic loss. If player $\mathrm{C}$ raises its $\mathrm{ER}$ bid-price from $140 \$ / A$ day to $200 \$$ /Aday, it can get ER with price $190 \$ / A$ day, but emitting unit pollution only can save $140 \$$ /day for C.

\section{CONCLUSION}

Optimal gross and distribution of ER should be worked out through cooperative game. This paper analyses the game of striving for ER and favorable PQ among all players in a certain PCC. The maximal unit price of ER pervious to players is the average expense saved from emitting unit pollution, and the maximal unit price of PQ service with quantity $y_{i}$ pervious to a player must be less than the production cost reduced by marginal unit PQ service. Uniform-price sealed auction makes all bidders provide their highest evaluation for ER and PQ service as their bid-prices, so PQSD can discern comprehensive information of all players. Furthermore, the optimal pollution gross worked out by PQSD can satisfy Pareto optimality and can maximize social integrative benefits. Uniform-price sealed auction is appropriate to distribution. The players who have high mitigation expense $v$ will get ER with high unit price. The players sensitive to $\mathrm{PQ}$ can enjoy $\mathrm{PQ}$ service with high price. Through ER distribution, electromagnetic environment resource and PQ investment are optimal distributed. Typical example indicates that researching optimal gross and distribution of electromagnetic pollution ER based on game theory is feasible and effective.

\section{REFERENCES}

[1] M H J. Bollen, Understanding power quality problems, voltage sags and interruptions. New York, IEEE Press, 2000.

[2] Fu Bo, "Principle and Application of Environment Economy," Shanghai City Layout, 2000, 5:11-16.

[3] Owen Guillermo, Game Theory, San Diego: Academic Press, 1982.

[4] E. Rasmussen, Games and Information: An Introduction to Game Theory, Oxford: Blackwell, 1989.

[5] J. Nash, "The Bargaining Problem," Econometrica, vol. 18, pp. 155 162, Feb. 1950.

[6] J. Nash, "Equilibrium Points in n-Person Games," Proceedings of the National Academy of Sciences of the United States of America, vol. 36, pp. 48 49, Jan. 1950.

[7] J. Harsanyi, R. Selten, A general Theory of Equilibrium Selection in Games, Cambridge: MIT Press, Jun. 1988.

[8] J. Driesen, T. Green, T. V. Craenenbroeck, et al, "The Development of Power Quality Markets," in Proc. 2002 IEEE Power Engineering Society Winter Meeting, pp. 262 267.

[9] Guanghou Jin, Gengyin Li, Ming Zhou. "Study on the Theory of Power Quality Market," Automation of Electric Power Systems, vol. 28, no. 12, pp. 1 6, Jun. 2004

[10] U. Baumgartner, C. Magele, W. Renhart, "Pareto Optimality and Particle Swarm Optimization," IEEE Transactions on Magnetics, vol. 40, pp. 1172 1175, Feb. 2004.

[11] Zuwei Yu, "NS Pareto optimality versus Nash equilibrium [deregulated electricity markets]," IEEE Power Engineering Review, vol. 22, no. 12, pp. 49 51, Dec. 2002.

[12] Min Huang, "Introduction of General Auction," Price Monthly, p. 35, Feb. 1995.

\section{BIOGRAPHIES}

Guanghou Jin was born in Jilin province, China, on Nov. 14, 1977. He received the B.S. degrees in power system and its automation from North China Electric Power University (NCEPU) in 2000. Now he is a doctoral student in NCEPU, and his research areas of interest include power quality and electricity market.

Gengyin Li (M'03) was born in Hebei Province, China, on May 18, 1964. He received the B.S., M.S. and Ph.D. degrees, all in Electrical Engineering, from North China Electric Power University (NCEPU) in 1984, 1987 and 1996 , respectively. Since 1987, Dr. Li has been with the Department of Electrical Engineering at NCEPU, where he is currently a professor and deputy head of the Department. His research interests include electricity markets, power quality, analysis and control of power systems, and new transmission and distribution technologies.

Ming Zhou received the B.S. and M.S. degrees in Electrical Engineering from North China Electric Power University (NCEPU) in 1989 and 1992, respectively. Now she is pursuing Ph. D. degree at NCEPU. Since 1992, Ms. Zhou has been with the Department of Electrical Engineering at NCEPU, where she is currently an associate professor. Her areas of interest include AI applications to power systems, electricity markets, and power system operation and management.

Yixin Ni (SM'94) received her B. Eng., M. Eng., and Dr. Eng. degrees all in electrical engineering, from Tsinghua University, China. She was a former Professor and Director of National Power System Lab, Tsinghua University and now is with the University of Hong Kong. Her interests are power system stability and control, FACTS, AI applications in power systems and power markets. 